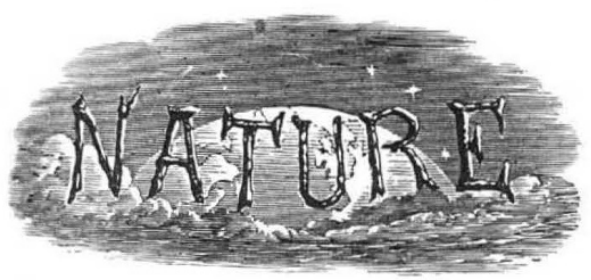

THURSDAY, FEBRUARY I0, I92I.

Editorial and Publishing Offices:

MACMILLAN \& CO., LTD.,

ST. MARTIN'S STREET, LONDON, W.C. 2.

Advertisements and business letters should be addressed to the Publishers.

Editorial communications to the Editor.

Telegraphic Address: PHUSIS, LONDON.

Telephone Number: GERRARD 8830.

\section{The Promotion of our Optical Industries.}

THE Government has promised to introduce in 1 the House of Commons early next session a Bill to safeguard and foster certain key industries in this country. Of these the optical glass and optical instrument industries deserve special consideration, for their importance is likely to be overlooked because they are relatively small industries, not employing large aggregations of capital or big numbers of firms and employees. It is dangerous for any nation to estimate the value and necessity of a particular industry by taking account merely of the capital sunk in it and of the number of people it employs. It is rather to the character of the industry and to the part it plays in the industrial life of the nation, both in peace and in war, that we must look if we are rightly to measure its intrinsic national value.

There are differences of opinion as to the best method of promoting the development of an incipient industry, whether by subsidies or by safeguards against unrestricted and unregulated foreign competition, but there is none as to the need for immediate action in the case of industries which are essential to the proper functioning of the nation's industrial system in peace and are vital to its safety in war. Adequate measures must be taken to foster these key industries, regardless of whether a general economic prinoiple, sound in ideal circumstances or as a general proposition, is violated.

It is not difficult to show that the manufactures of optical glass and of optical instruments fall in this category. First, it must be realised that the No. 2676 , VOL. IO6] manufacture of optical instruments in this country stands or falls with the manufacture of optical glass in this country. If the British optical instrument industry is to be maintained and to develop so as to turn out products equal, at least, to the best products of other nations, it must not be dependent on foreign sources for the supply of optical glass, but must have an adequate home supply, equal, again, at least to the best available anywhere. Owing mainly to our national neglect of scientific workers, supremacy in the optical glass industry, which was established in this country as early as 1837 , passed over to Germany, the Government of which had the insight and the foresight to gauge its actual and potential value. Not only did the Prussian Government bear the expense of the prolonged series of scientific investigations commenced by Schott and Abbe in $188 \mathrm{I}$, but also, in order to capture the world trade, large State subsidies were made continuously to the industry down to the declaration of war in I9r4. In that year there was but one firm manufacturing optical glass in the British Empire, with the consequence that during the first year of the war our armies and our fleets could not be equipped with the optical glass required.

By the intensive research of our scientific workers; by lavish expenditure; by the energetic enterprise of manufacturers in building workshops, installing plant, and, under conditions of great difficulty, training labour to perform the highly skilled operations needed, these deficiencies were overcome; and by the end of the war British optical glass was as good as German, and it was being produced in quantities sufficient to meet every demand. The optical instrument industry developed correspondingly, and instruments for all the varied purposes of the Army, the Navy, and the Air Force were manufactured equal to, and in many cases surpassing, the best that Germany could make. The position now is that we have the buildings, the plant, the organisation, the technical knowledge and the technicians, and the skilled labour needed to maintain these industries at their present high level of efficiency. Moreover, as a guarantee of future progress, the industry has established the British Scientific Instrument Research Association, and the Imperial College of Science and Technology has formed a Department of Technical Optics, so that the study of this branch of science, hitherto neglected in this country, may be raised to the highest university status.

It is undeniable that the preservation of the C C 
optical glass and optical instrument industries is absolutely vital in war. The skilled labour needed for this industry cannot be hurriedly improvised, as it can and was, for example, in the engineering trades. There is no kindred industry from which, for example, the optical glass grinders and polishers can be drawn in time of emergency. The optical glass maker and the optical instrument maker require a long training, and if these industries are allowed to decline and another war occurs, we shall find ourselves in a position more dangerous even than was our situation in I9I4.

A flourishing and efficient optical instrument industry is not less vitally important to the nation's peaceful pursuits than it is for purposes of warfare. The general use of optical instruments in industries is growing and must grow. The increasing use of the microscope in the textile and steel industries, and the application of the polarimeter for testing purposes in the sugar and essential oil industries, are but two of many examples that could be cited to show the growing dependence of our great national industries upon the optical instrument industry. The development and perfection of optical instruments and the invention of new types in this country will be brought to a standstill unless the instruments are manufactured here, where British inventors and designers can keep in close touch with the manufacturers. Moreover, this industry, springing directly from the loins of science, and progressing as scientific knowledge widens, is one of the most highly skilled industries we have. Its expansion means a definite increase in the numbers of technical scientific workers and of the most highly skilled artisans; and the national wealth, in any comprehensive conception of the term, must be increased by the increase of the numbers of such educated and skilled classes.

What is the position of these industries to-day? As the Daily Telegraph says in a leading article on January 6: "The industry is again exposed to the full blast of German competition, more formidable now than ever because of the state of the German exchange." Open competition, in these abnormal circumstances, is impossible.

There are two main objects which the Bill to be introduced should secure and reconcile. On one hand, if the industry is to be saved, the manufacturers must be protected from foreign competition aggravated by the state of the exchange; and, on the other, the users of scientific instruments must not be prejudiced or hampered, either by being unable to obtain the best instruments or by having to pay an extravagant price for them These apparently conflicting interests are not merely reconcilable; they are interdependent. If the British optical instrument industry should dwindle and die, the scientific users of instruments will be at the mercy of foreign manufacturers, they will have to pay a heavy price for such dependence, and they will be handicapped as compared with scientific workers in foreign countries possessing a flourishing scientific instrument industry. Similarly, if the scientific users cannot obtain the best instruments for their work, or if they have to pay an exorbitant price for them, their work will be hampered, their demand for instruments will decrease, and the manufacturers will ultimately suffer.

The industries, through the British Optical Instrument Manufacturers' Association, ask shortly for the following measures of protection :-

(I) No optical glass or scientific instruments to be imported into this country for a period of, say, seven years, except under licence.

(2) Such licences only to be granted in respect of goods which are not being made in Great Britain in the required quantities or of the required quality.

(3) An expert licensing committee to be set up.

(4) The optical instrument manufacturers are prepared, in order to guarantee reasonable prices, to submit to a control of profits.

The manufacturers are satisfied and confident that, under such conditions for a limited period, they would be able to establish the optical glass and optical instrument industries on a sound and stable basis, and also be able at the end of the period to meet any foreign competition in the open market. On the other hand, unless they secure this limited protection, it is more than probable -indeed, it is almost certain-that the manufacture of optical glass in this country will cease, and that, in consequence, some of the largest British manufacturers of optical instruments will greatly curtail their production. The proposed measures seem to protect adequately the interests of the scientific users. Moreover, such a system of control of imports for a limited period seems preferable to anything in the nature of a permanent tariff. It is not likely to have on the industry the emasculating effect of a protective tariff; provided that the period be limited, and that the licensing committee adopt an enlightened policy, prohibition of imports, except under licence, is rather calculated to act as a stimulus on the development of the industry.

There is, finally, one point not dealt with in the No. 2676 , VOL. IO6] 
proposals outlined above. In return for this shield from danger during a limited period, the country may well ask: What guarantee is there that the manufacturers are taking due measures to promote and prosecute the scientific research and scientific methods on which alone ultimately these, or any other, industries can be made efficient and able to stand against foreign competition? The leading manufacturers have combined to form a scientific instrument research association, and in addition many of them are engaged continuously in scientific research. But it is not clear that all the manufacturers who are demanding the legislative measures outlined above are contributing in either or both of these ways to the advancement of the industry. It is worth considering whether the proposed licensing committee should not take this factor into consideration in any specific case in which it is asked to grant or to refuse a licence.

\section{British Mammals.}

British Mammals. Written and illustrated by A. Thorburn. (In two volumes.) Vol. i. Pp. vii $+84+25$ plates. (London: Longmans, Green, and Co., I920.) Price Iol. Ios, net two vols.

$T^{\mathrm{HE}}$ success of "British Birds" and "A Naturalist's Sketch-book" has induced Mr. Thorburn and his publishers to issue companion volumes on "British Mammals," the first of which is now before us. Although the subject of our native beasts has already been somewhat exhaustively dealt with by Millais, Barrett-Hamilton, Harting, Lydekker, Coward, Adams, etc., there is yet room for Mr. Thorburn's book, because he is an artist-naturalist of such unique quality and observation that anything he may give us is worthy of publication and permanent value. In his case the common truism that there is always room at the top applies definitely. Pictures of natural history are always in demand, and we cannot have too many of those of the highest quality, since the exponents who possess genius are so few. Wherefore, even if the author's text is short, it is quite sufficient and extremely accurate so far as it goes, whilst the illustrations of the various species and subspecies, especially the smaller ones, are of such remarkable accuracy and beauty that it is not too much to say they have not been, and never will be, surpassed. Where Mr. Thorburn excels all other artists of mammals or birds is in his supreme rendering of the colour and texture of fur No. 2676 , VOL. IO6] and feather, as well as in his perfect association of natural background with the subject under treatment. He also introduces just the right botanical features found in association with the creatures he depicts, and skilfully inserts little and surprising notes of colour, such as a bluebell, an orange-tip butterfly, a golden kingcup, or a humble daisy, which of ten makes a charming picture out of what is really a dull and unattractive subject. This is pure skill, and the result of a severe artistic training combined with a knowledge of Nature.

Those of us who collect books of naturalist history find that there are few the text and illustrations of which stand the test of years. Processes of reproduction, as well as science and observation, are apt to become out-of-date and useless to the practical naturalist of to-day, since within the last few years this class of art and literature has reached a level never approached in past times. "The value of a book," once said Lord Rosebery, "is its price in the second-hand catalogues." Wherefore it behoves us, in these days of heavy expenditure and high taxation, to purchase our treasures with an eye to the future, and those of us who can afford a "Thorburn" book will be wise, for the work of this great artist must be limited, and will certainly rise in value.

The artist's pictures of dormouse, hedgehog, badger, fox, shrews, and various species of bats are quite little gems. His eye sees with PreRaphaelite exactness almost every hair on the lesser shrew, the smallest mammal in the world, and gives it that delicious softness which it possesses. If there is one picture that is a tour de force, it is the mole, a very difficult creature to paint. We have kept a mole alive and seen it gobbling a worm with the almost indecent haste so admirably depicted. There is the correct and strenuous position of the hind-legs, the holding of the powerful fore-paws, and the perfectly rounded line of the head as it gobbles its prey with a true gourmand's rapidity. Most artists would be content to paint just a dead mole, but Mr. Thorburn gives it life and character. Space does not permit us to criticise the numerous plates in which the artist has succeeded in giving us satisfactory renderings of our native beasts. $\mathrm{He}$ has a critical audience to satisfy, since he is apt to think that we now know our own mammals, few in number though they are; but special attention may be directed to the bats, which, although unlovely things, yet require an accuracy of delineation that calls for the highest care and exactitude. Mr. Thorburn has evidently taken the trouble to 